\title{
Transplantation Ethics: Old Questions, New Answers?
}

\author{
MICHAEL DEVITA, MARK P. AULISIO, and THOMAS MAY
}

The first reported successful kidney transplantation occurred in 1954, between twins. ${ }^{1}$ Since then, organ donation and transplantation has become less a medical marvel than a common expectation of patients with a variety of diseases resulting in organ failure. Those expectations have caused demand for organs to skyrocket far beyond available supply, fueling an organ shortage and resulting in over 60,000 patients on transplant waiting lists. In this special issue, our contributors attempt to shed new light on some of the many old ethical questions raised by transplant in the contemporary context of extreme scarcity.

What has contributed to these increased expectations and conditions of scarcity? A number of events have contributed to the growth of transplantation medicine and elevated public expectations. First, advances in medical science have improved prevention and treatment of the two major obstacles to successful organ transplantation: (1) ischemic injury to the donor organ during the procurement and implantation process, and (2) immunologic rejection by the recipient after

The section editors gratefully acknowledge the Ladies Hospital Aid Society of Western Pennsylvania, The Jewish Healthcare Foundation, and the Center for Organ Recovery and Education for their generous financial support of this project. Additionally, the University of Pittsburgh Consortium Ethics Program provided necessary administrative assistance. transplantation. Early recipients had poor outcomes. In 1971, for example, only about half of transplanted kidneys were still functioning after one year. ${ }^{2}$ Throughout the 1970s and 1980s, introduction of improved methods of preventing ischemia through more rapid procurement by surgeons and infusing cold organ-preserving solution meant patients received healthier organs. At the same time, new medicines such as cyclosporine and FK506 dramatically altered the progression of rejection, ultimately resulting, for example, in 1-year organ function rates of $90 \%$ or better for kidney recipients. Second, as outcome improved, the number of indications for transplantation expanded. New classes of potential transplant candidates included both sicker patients and those with less severe disease. Third, governmental and nongovernmental funding for transplantation research, as well as reimbursement from insurance companies, provided a financial impetus to create programs for organ transplantation. Thus, throughout the 1980s, transplantation medicine became a mainstream enterprise for larger hospitals, which caused the number of transplant programs to balloon and created intense competition for organs not only among patients but by institutions.

Although increased organ availability will reduce the wait for organs, until supply outstrips demand, care- 
givers will continue to have a responsibility to fairly distribute this precious resource. Organs differ importantly from other scarce healthcare resources, such as medications. In theory, greater quantities of medications can always be produced. Organs, however, for now and the foreseeable future, simply cannot be manufactured. Thus, triage will remain an essential part of the organ transplantation process for years to come.

This special section is devoted to examining issues raised by the continuing crisis of organ donation and allocation in these conditions of scarcity-old questions raised in new ways and ever in need of new answers. These issues range from macro policy issues, such as whether national or regional allocation schemes might be more justifiable and whether ethical issues in organ transplantation can even be addressed in a system infected by injustice and unequal access; to more narrow and novel questions, such as whether a father ought to be permitted to donate his only remaining kidney to his needy daughter or whether parents ought to be permitted to have a child partly for the purpose of procuring matching organs or tissue for one their other presently existing needy children.

James Childress, in "Putting Patients First in Organ Allocation: An Ethical Analysis of the U.S. Debate," examines the United Network for Organ Sharing (UNOS) system of allocation, which prioritizes organs for use within the particular region from which donation came (before the organs are offered to patients outside that region). Specifically, he focuses on what criteria for allocation might be ethically defensible. Maintaining that organs are a resource of the national community because "accidents of geography are morally irrelevant," Childress suggests that "just" considerations for organ allocation include severity of illness and time on the list. Thus, Childress places himself squarely on the side of the U.S. Department of Health and Human Services (HHS) in the controversial UNOS-HHS debate.

Laura Siminoff and Mary Beth Mercer, in "Public Policy, Public Opinion, and Consent for Organ Donation," examine the possible ramifications of existing and proposed programs designed to increase donation of organs on public attitudes and donor rates. They argue that the public tends to support programs to increase donation only if individuals do not perceive that access to healthcare will be restricted as a result or if donation is too highly incentivized (raising the motivation for abuse). Thus, they conclude that despite overwhelming public support for donation, proposals that ignore these cultural concerns will be ineffective or counterproductive.

Rachel Ankeny, in "The Moral Status of Preferences for Directed Donation: Who Should Decide Who Gets Transplantable Organs?," addresses preferences of individuals in donating toward or away from certain groups. She examines the defensibility of this practice, with an eye toward balancing the increase in the number of donated organs that might result against concerns for social justice. According to Ankeny, most arguments in favor of directed donation allocation schemes appeal to utilitarian grounds for justification - that is, they ultimately rely on the claim that more organs will be procured thus benefiting a greater number of people. While allowing that personal, emotional, and family attachment may be an acceptable basis of directed donation to specific individuals, Ankeny argues that allowing directed donation toward or away from certain groups amounts to an individual having a preference to limit others' options. So-called exter- 
nal preferences (drawing on Dworkin's notion) are counter to or at least undermine the utilitarian basis that is supposed to justify directed donation in the first place.

Ryan Sauder and Lisa Parker, in "Autonomy's Limits: Living Donation and Health-Related Harm," examine an unusual case of directed donation in which a father wishes to donate a second kidney to his daughter. They evaluate both the perspective of the possible donor and the moral agency of healthcare providers in procuring the second kidney. Sauder and Parker conclude that these currently rare and unusual cases should be treated much like any other living donation, ensuring informed consent of the donor followed by the healthcare team's assessment of available alternatives and potential "harm" to the donor. These donations may go forward if and only if there are no viable alternatives coupled with the prospective donor's acceptance of the benefit and the harm (assessed in light of his or her values).

In another unusual example of directed donation, some parents have procreated, in part, for the purpose of obtaining matching tissue or organs needed to save the life of one of their other already existing children-in other words, having a child to save a child. Mark P. Aulisio, Thomas May, and Geoffrey Block, in "Procreation for Donation: The Moral and Political Permissibility of 'Having a Child to Save a Child,'" examine the issues this raises and whether this form of directed donation should be allowed. They argue, first, that as a matter of social policy there is no justificatory ground for prohibiting parents from having a child to save a child; and, second, that whether or not donation should go forward in any particular case of this type should depend on, among other things, satisfying a "best interest of the donor" standard at the time of donation just as it does in typical cases of minors and livingrelated donation.

Whereas legislative initiatives, directed donation, and other controversial practices such as nonheartbeating organ donation have their supporters and critics, it is undeniable that if no organ shortage existed, the practices would be viewed very differently. Of course, debates over how to increase donation and who should be allowed to donate to whom presupposes that transplantation is on the whole "good."

In considering the crisis in organ donation it is important to recognize the moral and religious values that contribute to deciding whether organ donation is right or wrong. Aaron Mackler, in "Respecting Bodies and Saving Lives: Jewish Perspectives on Organ Donation and Transplantation," explores the Jewish tradition for organ donation as an example of the interplay between respect for the dead and the imperative to save lives (which, at first glance, seem to conflict). Mackler concludes that, in the Jewish tradition, the relatively minor harm to the donor is reasonable given the benefit to the person in need.

We conclude this introductory overview with a few general remarks concerning organ donation and transplantation today. First, there is a tendency to view organ transplantation from the perspective of the recipients: how many lives will be lost, how many years will be gained, how much will it cost to save or improve each life? The huge waiting list is tangible evidence of a national hunger for organs. Because of the need, people being asked to donate may view the request with skepticism, if not outright cynicism ("Are medical actions being taken to promote the health of my loved one, or are they motivated by the need to "get at" organs?"). In a sense, as long as justifications arise solely from need, 
they will be tainted. Therefore, perhaps, there should be reduced emphasis on the need for organs, because as perception of need increases, there can be an increased perception that people may go to greater lengths (perhaps even illegal or unethical lengths) to get organs. Fear and defensivenessinstead of altruism - may reign. There are some data to support the hypothesis that this may be already occurring.

A paradigm shift toward viewing organ donation from the perspective of the donor is needed. If better care for the dying is instituted, then perhaps the potential donor's cultural and trust concerns may be overcome. If people perceive that they are receiving high-quality healthcare throughout their illnesses, it may result in improved perception of healthcare overall. People may be more likely to contribute to a system (by donating organs) that they perceive to be fair, compassionate, and high quality. Of course, to improve the perception of quality and equitable healthcare, improved access is needed.

Second, the issues confronting ethicists, caregivers, and patients in 2001 are largely the same as those that were being debated almost 50 years ago. Basic issues such as whether donors are dead, who may be considered an ethically appropriate donor, and how organs should be allocated remain changed only by an increasingly pressing need for organs. There is considerably more empirical work con- tributing to the debate today than in the 1960s; nevertheless the issues are not dramatically different-indeed we really do have "old questions" seeking "new answers."

Finally, even though the articles in this special section span a wide range of issues in organ transplantation and donation, all are heavily impacted by the need for organs in the contemporary context of extreme scarcity. Readers may have a sense that some of the arguments are motivated more by a belief in the positive good "end" of organ transplantation rather than the ethics of the "means" of obtaining organs. There is an inevitable tension here that cannot be alleviated until the context of scarcity itself disappears. As we continue to address ethical issues in organ donation and transplant, it is our sincere hope that advances in transplant technology will fulfill their considerable promise, eliminating the context of scarcity and forever shifting the focus and terms of the transplant ethics debate. Until then, we will continue to look for new answers to these old and stubborn questions.

\section{Notes}

1. Merrill M, Murray J, Harrison J, Guild W. Successful homotransplantation of the human kidney between identical twins. JAMA 1956;160:277-82.

2. ACS/NIH Information Registry. U.S. Kidney Transplant Fact Book. Bethesda: National Institutes of Health, 1972. 